\begin{tabular}{|c|c|c|c|}
\hline & Eurasian Academy of Sciences & Eurasian Academy of Sciences S & nces Journal \\
\hline (t) & Social Science Journal (Onternatiol Refereed \& Indexed) & $2016 \quad$ Volume:7 & S: $208-216$ \\
\hline \multicolumn{4}{|c|}{$\begin{array}{c}\text { Published Online January } 2016 \text { (http://socialsciences.eurasianacademy.org) } \\
\text { http://doi.org/10.17740/eas.soc.2016.V7-13 }\end{array}$} \\
\hline
\end{tabular}

\title{
INVESTIGATION OF THE SHOULDER HALAY IN AREA TOKAT
}

\author{
Özgür Zafer Alkaya*, Mustafa Kaya**, Kürşad Gülbeyaz *** \\ * Gaziosmanpaşa Üniversitesi, **Gaziosmanpaşa Üniversitesi, ***Muğla Sıtk1 Koçman \\ Üniversitesi \\ E-mail: ozalkaya60@hotmail.com,efe588@hotmail.com, kusadgulbeyaz@hotmail.com
}

Copyright (C 2016 Özgür Zafer Alkaya, Mustafa Kaya, Kürşad Gülbeyaz. This is an open access article distributed under the Eurasian Academy of Sciences License, which permits unrestricted use, distribution, and reproduction in any medium, provided the original work is properly cited.

\begin{abstract}
This Study was conducted to examine the way how shoulder dance was acted in Tokat district and what sense it has at the present. Tokat of which the history backs BC Dates to the year 3000 is one of the most important settlements in Central Black Sea region. Tokat hosted many nations and people starting from the ancient Byzantine period such as Byzantine, Arab , Persian , Mongol and Turks until today. . This " multi-culturalism" is obviously manifested in the material and spiritual cultural values. The rich and deep-rooted culture in this district can be observed in the diversity of movements, figures and acts in folk dances. Both folk dance colthes and daily clothes are the evidence of the richness and diversity of the cultural heritage . Although Tokat's in the transition zone, it is mainly classified as "Halay Dance Type" in terms of Folk Dances an done of the oldest dance known in Tokat is still "shoulder " dance . It is also called "arbor"dance. Shoulder ( arbor ) dance used to be acted by men in the past. However, it is known that women - men are played in a mixed dance especially after the spread of folk dance competitions with the "staging" fact since the end of the year 1970. It is obvious that this dance has a different feature among Turkish folk dance because women perform the dance on the shoulder of men. Although different meanings assigned in the past to shoulder dance, today it is thought to symbolize "the value given to women ".
\end{abstract}

Keywords: Tokat, folk dances, halay, folklore, costume, clothes, woman.

\section{TOKAT YÖRESI OMUZ HALAYININ İNCELENMESI}

\section{ÖZET}

$\mathrm{Bu}$ çalışma, Tokat yöresi omuz halayının oynanış şekli ve oyunun günümüzde ne anlam taşıdığının incelenmesi amacıyla yapılmıştır. Orta Karadeniz Bölgesinin önemli yerleşim merkezlerinden biri olan Tokat'ın tarihi M.Ö. 3000 yıllarına kadar dayanmaktadır. Tokat günümüze kadar Antik Bizans döneminden başlayarak Bizans, Arap, Fars, Moğol, Türk gibi birçok millet ve kavme ev sahipliği yapmıştır. Bu “çok kültürlülük" Tokat'ın maddi ve manevi kültürel varlıklarında açıkça gözlenmektedir. Bu bölgenin ne kadar zengin ve köklü bir kültüre sahip olduğunun bir göstergesi yörede oynanan halk oyunlarındaki oyun, hareket ve figürlerin çeşitliliğinden anlaşılmaktadır. Ayrıca gerek günlük giyimdeki gerek halk oyunları kıyafetlerindeki zenginlik ve çeşitlilik de bu kültür zenginliğinin başka bir göstergesidir. Halk oyunları açısından geçiş bölgesinde olmasına rağmen ağırlıklı olarak "halay türü” sınıfına giren 
Tokat'ta bilinen en eski oyunlardan biri de "omuz" halayıdır. Bu halaya "çardak" halayı da denilmektedir. Omuz (çardak) halayı eskiden sadece erkekler tarafından oynamakta idi. Fakat özellikle halk oyunları yarışmalarının yaygınlaşmasından sonra "sahneleme" olgusu ile birlikte 1970'li yılların sonlarından itibaren kadın - erkek karma bir şekilde oynandığı da bilinen bir gerçektir. Omuz Halayı Türk halk oyunları içerisinde erkeklerin kadınları omuzlarına alarak icra edilmesinden dolayı farklı bir özellik taşıdığı aşikârdır. Geçmişte farklı anlamlar taşısa da günümüzde kadınların omuza alınarak oynanması açısından "kadına verilen değeri" simgelediği düşünülmektedir.

Anahtar Kelimeler: Tokat, halk oyunları, halay, halk bilimi, kostüm, giysi, kadın.

\section{GíRiş}

Geçmişten günümüze düğünler, şenlikler, törenler, bayramlar ve çeşitli toplantılarda oynanan halk oyunları ve seyirlik oyunlarımız milli kültürümüzün vazgeçilmez öğelerindendir. Türk folklorunun çok zengin bir dalı olan halk oyunları ulusumuzun ortak duygu, düşünce ve yaşantısını yansıtan sanat değeri üstün bir anlatım aracı niteliği taşırlar(Aydın; 1979: 10). Çok zengin bir oyun kültürüne sahip olduğumuz bilinen bir gerçektir. Halk oyunlarını izlerken, yurdumuzun değişik yörelerinde yaşayan insanların örf, adet ve geleneklerini, inanışlarını ifade ettiğini, tabiat ve diğer canlılarla yaptıkları mücadeleyi anlatan özellikler taşıdığını görürüz. Her sanat dalında olduğu gibi halk oyunlarımızda insanı anlatır. Bu nedenle oyunlarımızın altında kaynağı çok eskiye dayanan, bugün unutulmaya yüz tutmuş derin manaların gizlendiği bilinmektedir(Ay; 1999: 30).

Halk oyunları türleri hemen her bölgede birbirinden farklı özellikler taşırlar. Birçok araştırmacı, yazar ve bilim adamı halk oyunlarını çeşitli açıları itibarı ile tasnif etmişlerdir. Bazıları halk oyunlarını çeşitli türlere ve bölgelere ayırmışlardır. Bu ayırım oyunların daha çok hareket, müzik, kıyafet, cinsiyet gibi özellikleri göz önünde bulundurmuşlardır. Fakat Türk halk oyunları bilimsellik adına hareket açısından incelendiğinde 5 (beş) ana tür altında toplanmaktadır. Bu ana türlerden bir tanesi de "halay" türüdür.

Orta Anadolu ile Güneydoğu Anadolu bölgemizde; toplu, düz, dizi halinde ve disiplinli bir biçimde oynanan oyunların tümüne birden "halay" denir(Baykurt; 1976: 124-125, Ekmekçioğlu ve ark; 2001: 28, Aydın; 1979: 21-24, Keskin; 1975: 5, Baykurt; 1996: 50, Eroğlu; 1999: 143, Karahasan; 2003: 8). Tokat yöresi, Türk halk oyunlarının sınıflandırılması açısından halay grubu sınıfina girmektedir(Karahasan; 2003: 8, Su; 2000: 6). Toplu icra edilen bu oyunlar kadın oyunları, erkek oyunları ve karma (kadın erkek birlikte) icra edilen oyunlar şeklinde sınıflandırılmıştır(And; 2007: 63). Ayrıca bu oyunlar genellikle ağırlama ve yeldirme olmak üzere iki bölümden oluşmaktadır. 
Tokat yöresinde yaygın olarak oynanan halaylardan biri de "omuz halayı", başka bir adı ile "çardak halayıdır". Omuz halayının yörede bilinen iki farklı öyküsü vardır. Bir anlatıma göre; eskiden gelin, gelin alıcılarla birlikte baba evinden ata bindirilerek getirilir. Damat evine gelindiği zaman onları karşılayanlar bir yandan oyunlarını oynarlar, bir kişi çömelir ve gelinin üzerine basarak yere inmesine yardımcı olurdu. Kadını ve erkeğiyle her işte bir olan ve yardımlaşan yöre insanı omuz halayında da birlikteliği; dayanışmayı, düşmana karşı büyük görünmeyi, omuzlara alarak yüceltmeyi, sevince ortak olmayı anlatmakta ve böyle yorumlanmaktadır (Adıgüzel; 2004: 119).

Diğer anlatımda ise Turan Gülbeyaz; gelinin damat evine getirilmesi ile ilgili şu ayrıntıya özellikle dikkat çekmiştir: Eskiden at binen insanların attan inmelerini kolaylaştırmak amacıyla evlerin kapılarının yan tarafında "seki" adı verilen yüksekçe bir yer bulunurdu. Damat evine getirilen gelinler de aynı şekilde seki kullanılarak attan indirilirdi. Sekinin olmadığı evlerde ise gelinin attan inebilmesi için damadın birinci derece akrabalarından bir gencin eğilerek omuz vermesi ile gelin attan indirilir ve dualarla yeni evine girmesi sağlanırdı.

Bahattin Destebaşı, köy dügüülerinde gelin damat evine getirildiğinde attan indirilirken damadın yakın akrabalardan birinin eğilerek gelinin sırtına basıp inmesini sağladığını anlatmaktadır.

Şahin Bozdemir ve Yusuf Karagöz yörede müzisyenlik (zurna) yapmakta olup nerdeyse tüm köylerdeki düğünlere katıldıklarını ifade etmektedirler. Özellikle köy düğünlerinde ilk oyun olarak kesinlikle Tokat Ağırlaması oyununun oynandığını üzerine basarak söylemektedirler. Bu oyunun gelen misafiri karşılamak amacı ile oynandığını ifade etmişlerdir. Eskiden atla şimdilerde ise araba ile getirilen gelinin indirilmesi esnasında "gelin ağlatması" havasının çalındığını da vurgulamışlardır. Hatta şu detaya ise dikkat çekmektedirler. "Gelin damat evine getirildiğinde attan inmez, kayın babası ve kayın annesinin hediyelerinin ne olduğu söylenir, devamında gençler Tokat Ağırlaması oyununu oynarlar, bazı düğünlerde de oyunun içerisinde birbirinin omuzlarına çıkarlar. Bu esnada gelin ağlatması havası çalınır. Oyunun bitmesiyle birlikte müzik kesilir, gelin dualarla yeni evine teslim edilir." 


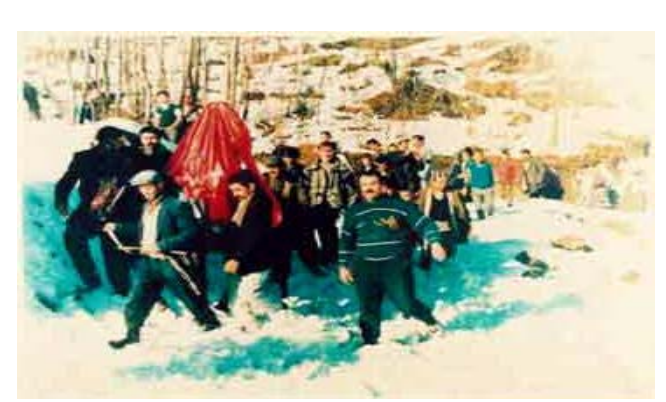

Resim: 1

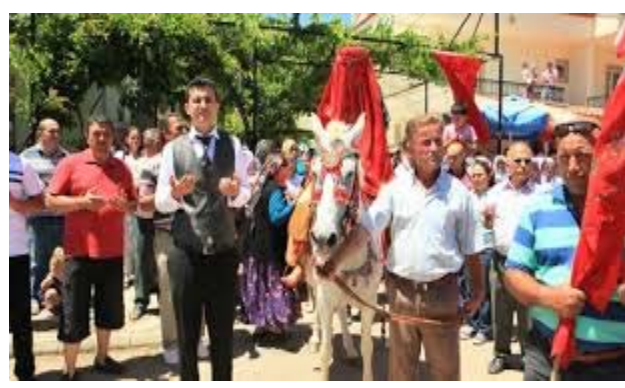

Resim: 2

Turan Erdem kaleme aldığı bir yazısında Omuz Halayı oyununun; 1965'li yıllarda Tokat merkez ilçeye bağlı Çatalkaya (Selük) Köyü’nden Mos'un oğlu lakabıyla bilinen zurnacı Süleyman efendi tarafından öğretildiğini ifade etmektedir. Oyunun öğretildiği yıllarda oyunlar kız-erkek birlikte oynanmadığı için sadece erkek oyuncular tarafından oynandığı, oyunun isminin ise "çardak halayı" olduğunu belirtmiştir.

Erdem aynı yazısında yer verdiği bir anısında bu konuyu şöyle anlatmaktadır: Bugün 77 yaşında olan annemi, 1984 yılı ocak ayında Tokat'ta okullar arasında yapılan halk oyunları yarışmalarını izlemek üzere spor salonuna götürdüm. Annem omuz halayını seyrederken; "Oğlum bu çardak oyununu nereden buldunuz?" deyince ben yine gafletten uyanıp "Anne bu oyunun adı omuz halayıdır" dedim. O ısrarla "Yok oğul, biz çocukken bu çardak oyununu büyüklerimiz düğünlerde arada bir oynar ve bizlerde ilgiyle seyrederdik" diyerek biraz da sitemli vaziyette "Sizler oyunları çok değiştirmişsiniz, bu oyunlar eskiden böyle oynanmazdı" dedi. Üzerinde fazla durmadan konuyu kapattık... Daha sonra bazı yaşı kişilerle yaptığımız sohbetlerde oyunun gerçek adının "Çardak oyunu” olduğu defalarca tekrarlandı. Ancak merak bu ya adının neden Çardak olduğunu araştırdığımızda ise; "Eskiden köy evlerinin giriş kısmının üst katında yer alan çıkıntılı balkona çardak denilirdi. Bu tip evleri taklit etmek gayesiyle çardak oyunu ortaya çıkmış oldu.” Diye cevap verilir(Erdem 1991: 42).

Burhan Kaçar; eskiden oyunun erkekler tarafından oynandığını üzerine basarak aktarmaktadır. İki katlı Tokat evlerindeki giriş kısmının üst katında yer alan, balkon görünümündeki bölüme "çardak" denildiğini; bu yüzden de oyunun adının "omuz halayı" değil “çardak halayı” olduğunu ifade etmektedir.

Bahattin Destebaşı oyunun iki katlı Tokat evlerini takliden oynandığından bahsetmektedir. Oyunun isminin de "çardak halayı" olduğunu, bu adı da Tokat evlerinin çardak bölümünden aldığını ifade etmektedir. 


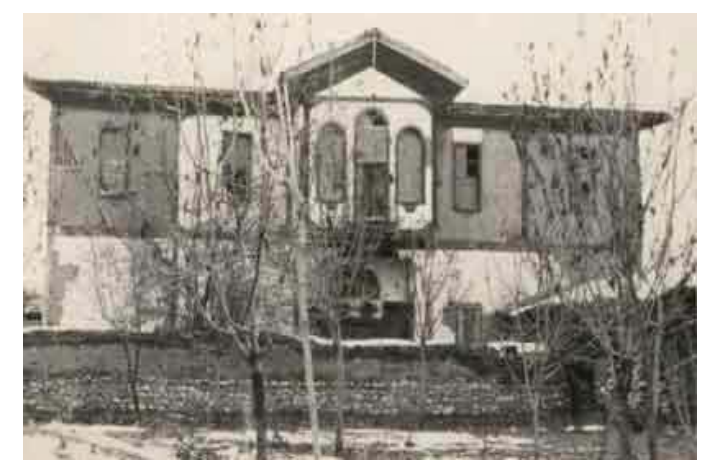

Resim: 3

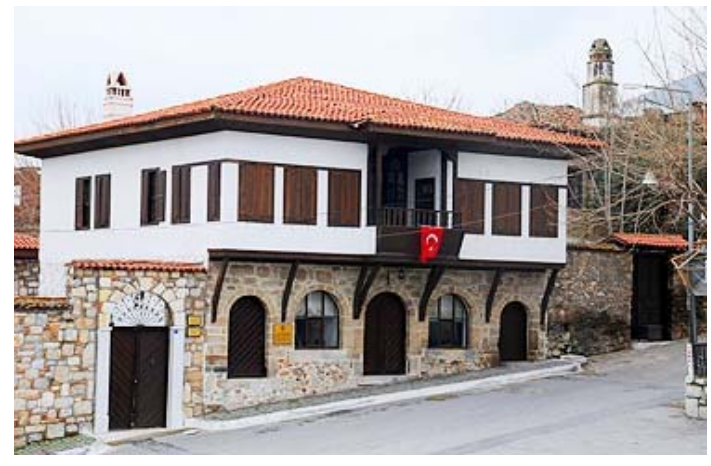

Resim: 4

\section{Materyal ve Metot}

Araştırmada literatür taramasının yanı sıra gözlem ve röportaj yöntemi kullanılmıştır. Tokat'ta halk oyunları ile uzun yıllar ilgilenen ve özellikle 50 yaş üzeri kişilerle görüşme yapılmıştır. Bu görüşmelerde omuz halayının oynanış şekli ile oyunun ne anlatmak istediği ve eski dönemlerde nasıl oynandığı ile ilgili sorular sorularak elde edilen bilgiler kayıt altına alınmıştır.

\section{Bulgular}

\section{Omuz (Çardak) Halayının Oynanış Şekli}

Omuz Halayı Tokat Ağırlaması oyununun içerisinde bir bölüm olarak yer alır. Tokat Ağırlaması oyunu yörede misafiri ağırlamak, karşılamak amacıyla oynanır. Düğünlerde oynan ilk oyundur ve her zaman oyuna Tokat Ağırlaması ile başlanır. Oyun selamlama ile başlar, ağırlama bölümü, yanlama bölümü ve yeldirme (hoplatma) bölümü ile son bulur. Oyununun ağırlama bölümü içerisinde yer alan çökme hareketinden sonra Omuz Halayına geçilir.

Omuz halayına "gelin ağlatması" denilen ve gelinin damat evine geldiğinde çalınan bir çeşit uzun hava ile başlanır. Omuza alacak oyuncular eller omuzlarda, beden dik pozisyonda, vücut ağırlı̆̆ı sağ ayakta olacak şekilde sağ kalçaya oturmuş, sol ayak ise taban yere tam basacak şekilde yana doğru açılmış şekilde beklenir (bkz. Resim:5-6). İlk önce omuza çıkacak oyuncular omuzlardan tutarak yerdeki oyuncunun sol dizine kendi sol ayağı ile basarlar (bkz. Resim:7). Daha sonra yerdeki oyuncunun sağ omzuna kendi sağ ayağını basarlar (bkz. Resim:8). Ve son olarak yerdeki oyuncunun sol omuzuna kendi sol ayağını basarak omuza çıkmış olurlar (bkz. Resim:9). Yani omuza çıkacak oyuncu bir nevi merdivene çıkar gibi diğer 
oyuncunun omuzuna çıkmış olur. Daha sonra yerdeki oyuncular dik şekilde ayağa kalkarak oyunu oynamaya hazır hale gelirler (bkz. Resim:10).

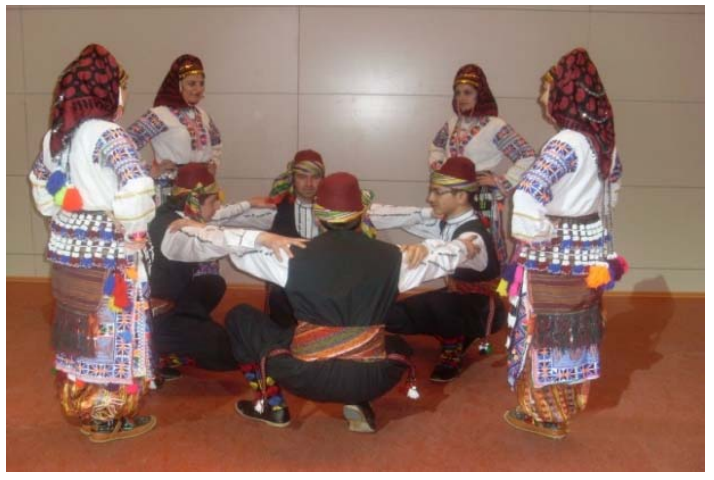

Resim:5

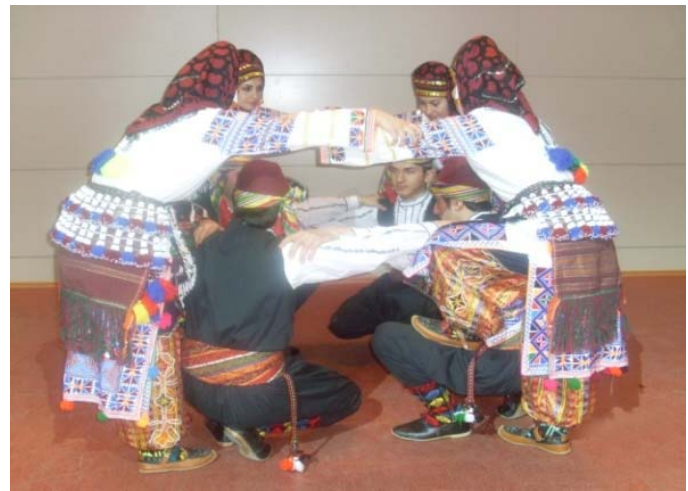

Resim:7

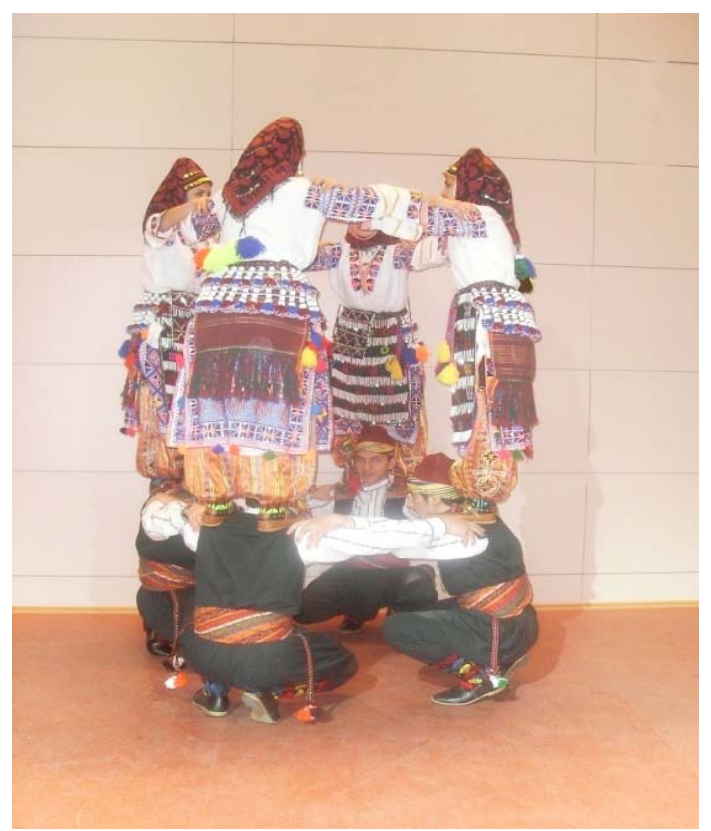

Resim: 9

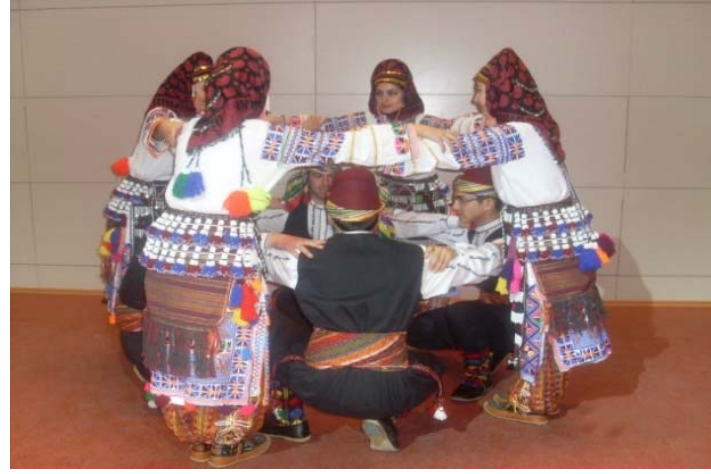

Resim: 6

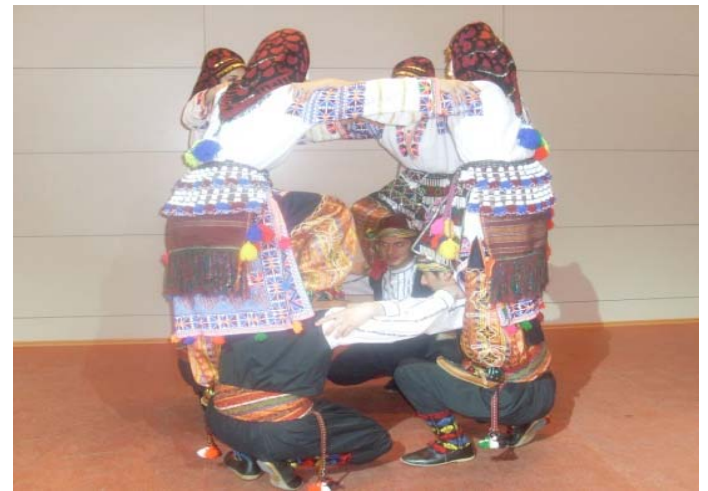

Resim: 8

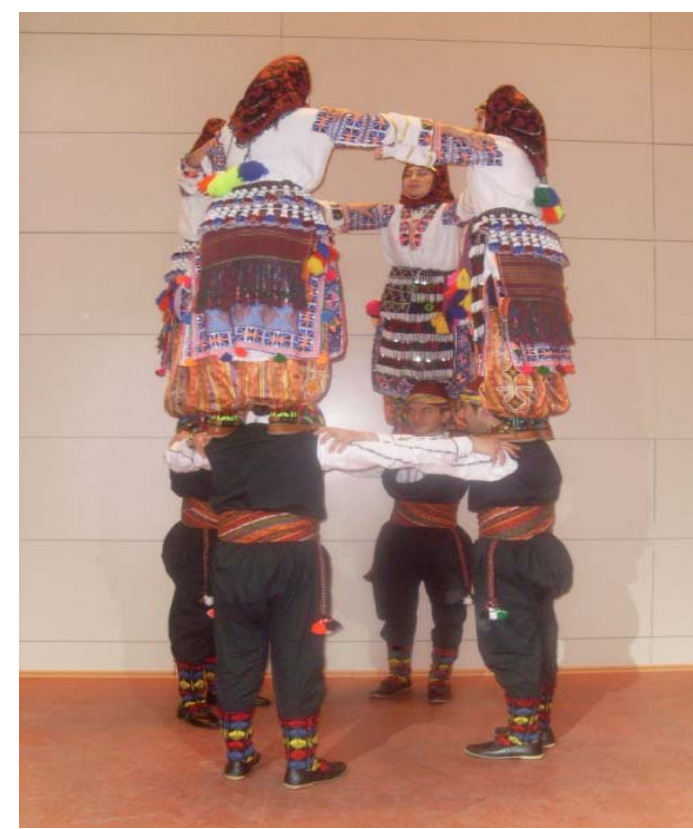

Resim: 10 
Yerdeki oyuncunun ayağa kalkması ile birlikte çalınan gelin ağlatması havası kesintiye uğratılmadan Tokat Ağırlaması oyununun ağırlama bölümüne bağlanır. Bu pozisyonda Tokat Ağırlaması oyunu oynanmaya başlar. Oyunda normale göre hareketler biraz daha sade, küçültülerek yapılır. Yana doğru yürüme hareketinde ayak diğer ayağı geçmez yanına basılarak kullanılır. Fakat daire formundaki oyun formu bozulmadan sağa doğru dönülerek oynanır. Ağırlama bölümü oynandıktan sonra yanlama bölümüne geçilir. Ayaklar yine diğer ayağın yanına getirilip basılarak kullanılır. Oyun formunda ve hareketlerde bir eksiltme yapılmaz. Yanlama bölümünden sonra gelin ağlatması havası tekrar çalınmaya başlanır, ayaktaki oyuncu yavaşça yere doğru çöker ve aynı pozisyonu alır. Omuza çıkan oyuncular da omuza çıktıkları şeklin simetrisi şeklinde tekrar yere inerler ve Tokat Ağırlaması oyununun hızlı bölümü oynanarak oyun tamamlanır.

Omuz halayının Tokat Ağırlamasının içerisinde bir bölüm şeklinde yer alması boşuna değildir. Omuz halayı gelin damat evine getirildiğinde gelinin attan indirilişini temsilen oynanmaktadır. Bunun için misafir karşılaması amacıyla oynanan oyunun içerisinde yer almaktadır ki gelin de damat evine girene kadar misafirdir. Omuzlara alma ve omuzlardan indirme esnalarında da gelin ağlatması havasının çalınması da bu yüzdendir. Yani o ana kadar misafir olarak kabul edilen gelin karşılanır, ağırlanır, indirilerek damat evine teslim edilir.

Eskiden oyununun zayıf olan erkeklerin güçlü olan erkeklerin omzuna çıkması ile icra edildiği kaynaklar tarafından aktarılmaktadır. Gazimihal omuz halayını "birkaç oyuncunun omzuna birkaç oyuncu çıkar, o şekilde iki katlı bir halka şeklinde oynanır" şeklinde tanımlamıştır(Gazimihal; 1999: 184). Demirsipahi ise omuz halayını üst üste oynanan halaylardandır şeklinde tanımlayarak halayın oynanma şeklini şu şekilde açıklamıştır. "Güçlü ve kuvvetli olan oyuncuların omzuna daha ufak ve zayıf olanlar iki bacaklarını omuzlarına bindikleri oyuncunun başını arasına alarak binerler. Omuz halayı bu şekilde oynanmaktadır” (Demirsipahi; 1975: 257-258).

Halk oyunları her dönemde çeşitli değişimlere uğrayarak günümüze kadar gelmiştir. Tokat yöresinde oynanan Omuz Halayı da bu bağlamda bazı değişikliklere uğramıştır. Özellikle halk oyunları yarışmalarının düzenlenmesi ile başlayan "sahneleme" çalışmalarının etkisi ile 
aslen erkekler tarafından oynanan oyun günümüzde karma (kadın - erkek) olarak oynanmaktadır.

Gerek gelinin omuza alınarak attan indirilmesi, gerek bayanların omuzlara alınarak oyunun oynanması yörede kadına verilen önemin açık bir göstergesidir.

\section{Tartışma ve Sonuç}

1. Omuz halayının her ne kadar iki katlı evleri temsili olarak oynandığı görüşü var olsa da gelinin misafir olarak karşılanması amacı ile Tokat Ağırlaması oyununun içerisinde oynandığı görüşü daha ağır basmaktadır.

2. Tokat Ağırlaması oyunu misafirleri karşılamak ve ağırlamak amacı ile oynanmaktadır. Omuz halayı ise gelinin damat evine girene kadar misafir olduğu düşüncesiyle Tokat Ağırlaması oyununun içerisine temsili olarak yerleştirilmiştir.

3. Gelin ağlatması ile omuzlara alınan erkekler yine gelin ağlatması havasının çalınması ile omuzlardan indirilir.

4. Baba evinden getirilen gelin varsa seki, yoksa damadın birinci derecede yakınının omuzlarına basarak attan indirilir.

5. Kültürel değiş̧im omuz halayında da gözlenmektedir. Aslen erkeklerce oynanan oyun günümüzde bayanlar omuzlara alınarak oynanmaktadır. Bunun haricinde başka bir değişikliğe uğramamıştır.

\section{REFERENCES}

\section{A. Yazılı Kaynaklar}

- And M. Oyun ve Bügü. İstanbul: Yapı Kredi Yayınları 2. Baskı, 2007.

- Karahasan T H. Yöresel Türk Halk Oyunları, Akın Yayınevi, İstanbul 2003.

- Su R. Türk Halk Oyunları, Kültür Bakanlığı Yayınları, Ankara, 2000.

- Ay G. Folklor (Halk Bilimi), Ayhan Matbaası, İstanbul, 1999.

- Erdem T. “Omuz Halayı mı? Çardak Oyunu mu?”, Tokat Kültür Araştırma Dergisi, Say1:2, Haziran 1991.

- Adıgüzel S. “Gülü Bardağ İçinde”, ISBN 975-270-025-X, Tokat 2004.

- Baykurt Ş. Türkiye'de Folklor, Kalite Matbaası, Ankara, 1976.

- Ekmekcioğlu İ, Bekar C, Kaplan M. Türk Halk Oyunları, Esin Yayınevi, İstanbul, 2001.

- Aydın C. Okullarda Halk Oyunları, Karınca Matbaası, İzmir,1979.

- Keskin E. Halk Oyunları Öğrenimi, Kadıŏglu Matbaası, Ankara, 1975. 
- Baykurt Ş. Türkiye’de İlk Halk Oyunları Semineri, Yapı Kredi Yayınları, İstanbul. 1996.

- Eroğlu T. Halk Oyunları El Kitabı, Mars Basımevi, İstanbul, 1999.

- Karahasan H. Yöresel Türk Halk Oyunları, Alkım Yayınevi, İstanbul, 2003.

- Demirsipahi C. Türk Halk Oyunları, İş Bankası Kültür Yayınları, Türk Tarih Kurumu Basımevi, Ankara, 1975.

- Gazimihal M. R. Türk Halay Oyunları Kataloğu, Kültür Bakanlığı Yayınları, Ankara 1999.

\section{B. Sözlü Kaynaklar}

- Bahattin DESTEBAŞI, 1949 Tokat Merkez Kervansaray köyü, emekli.

- Burhan KAÇAR, 1950 Tokat Merkez, öğretim üyesi.

- Şahin BOZDEMİR, 1962 Tokat Merkez Dereyaka (Miskincik) Köyü doğumlu, zurnac1.

- Turan GÜlBEYAZ, 1948 Tokat Merkez Aktepe (Bolos) Köyü doğumlu, emekli.

- Yusuf KARAGÖZ, 1962 Tokat Merkez Çubuklu (Arapköy) Köyü doğumlu, zurnac1. 